\title{
Enclaves globales agrícolas y migraciones de trabajo: convergencias globales y regulaciones transnacionales'
}

\author{
Global agriculture enclaves and labor migrations: global \\ convergences and transnational regulations
}

\author{
Natalia Moraes, Elena Gadea, Andrés Pedreño y Carlos De Castro \\ Departamento de Sociología y Política Social, Universidad de Murcia y Universidad Autónoma de Madrid \\ nmoraes@um.es,megadea@um.es, andrespe@um.es y c.decastro@uam.es
}

Recibido: 16.06.2011

Aprobado definitivamente: 13.12 .2011

\section{RESUMEN}

En las últimas décadas, la globalización del sistema agroalimentario ha dado lugar al surgimiento, a lo largo y ancho del planeta, de nuevos enclaves de agricultura intensiva. Su orientación hacia mercados externos, su elevada modernización tecnológica y productiva y su intensa utilización de mano de obra, han convertido a la agroindustria en un sector que dota de dinamismo a los territorios en los que se asienta y convierte estos espacios en el escenario de intensos procesos de movilidad del trabajo y el capital. Este artículo pretende mostrar cómo, a pesar de la diversidad de contextos, podemos identificar en estos territorios un conjunto de convergencias globales, entre las que cabría destacar un uso intensivo del trabajo asalariado, unas relaciones de empleo que exigen una alta flexibilidad y una norma de producción regida por la discontinuidad temporal de los cultivos y, sobre todo, por las demandas cambiantes de los mercados. Junto a estas convergencias, asistimos en estos espacios al surgimiento de nuevas formas de regulación transnacional de la producción y el trabajo, protagonizadas por las empresas transnacionales y las grandes cadenas de distribución.

Palabras Clave: Enclaves de agricultura intensiva, movilidad del trabajo, flujos migratorios, regulación transnacional del trabajo.

\begin{abstract}
In recent decades in the context of food globalization have emerged new enclaves of intensive agriculture. These enclaves of agricultural production have generated new patterns of mobility of transnational capital and of agricultural work. Its orientation towards external markets, its high technology and production modernization and its extensive use of labor have turned it into a sector that dynamizes the territories in which it sits. This article shows that, despite the heterogeneity of production sites scattered throughout Latin America and

\footnotetext{
${ }^{1}$ Este artículo se enmarca en el proyecto titulado SOSTENIBILIDAD SOCIAL DE LOS NUEVOS ENCLAVES PRODUCTIVOS AGRICOLAS: ESPAÑA Y MEXICO (ENCLAVES), dirigido por Andrés Pedreño Cánovas y financiado por el Ministerio de Ciencia e Innovación (2012-2014, CSO2011-28511).
} 
Southern Europe, there is a general trend in the production and working conditions toward precariousness. Given these conditions and their social effects, this article explores the social regulatory initiatives that have been deploying in these enclaves. First, this article social and analytically contextualizes the proliferation of new enclaves of intensive agriculture. Second, it then describes the new patterns of mobility and settlement of work that have contributed to the appearance of new enclaves of agricultural production in a context of increased local and global migration flows. New patterns of mobility and settlement are presented as indicators of the effects on social cohesion that are generating these productive territories. Third, we describe the new social composition of the labor market, showing their sexual and ethnic segmentation and precarious working conditions. Fourth, the paper indicates some of the many efforts of social regulation of these new production areas. To conclude, the findings concentrate on thinking about the complicated relationship between global productive convergences and transnational regulations.

KEYwORDs: Intensive agriculture enclaves, labor mobility, labor migration, transnational regulation of labor

\section{SUMARIO}

1.Introducción. 2.Cadenas globales agrícolas: movilidad del trabajo y del capital. 3.Circulaciones migratorias $\mathrm{y}$ condiciones de vida jornalera en los enclaves de agricultura intensiva. 3.1.Patrones de movilidad y condiciones de vida jornalera. 3.2.Asentamiento de migrantes, segregación y convivencia socio-espacial. 4.Convergencias y divergencias de las lógicas de empleo y condiciones de trabajo. 4.1.La constitución de los mercados de trabajo agrícola y la nueva estructura social jornalera. 4.2.La paradoja de la modernización tecnológica de los procesos productivos y de la precarización de las condiciones de trabajo. 5.¿Hacia una regulación transnacional de los derechos de los trabajadores y trabajadoras en la agricultura? 5.1.¿La Responsabilidad Social Empresarial como mecanismo de regulación laboral? 5.2. Instrumentos, nuevos actores y debates sobre la RSE. 5.3.Impacto de la RSE en las condiciones laborales de los trabajadores. 6.Conclusiones.

\section{SUMMARY}

1.Introduction. 2. Global agricultural Chains: mobility of labor and capital. 3.Migratory Chains and living conditions of workers in the enclaves of intensive agriculture. 3.1.Mobility patterns and living conditions of workers. 3.2. Migrants settlements, social segregation and socio-spatial coexistence. 4. Convergences and divergences of the employment models and working conditions. 4.1. The establishment of agricultural labor markets and its new social structure. 4.2. The paradox of technological modernization of production processes and precarious working conditions. 5. Towards a transnational regulation of the rights of workers in agriculture? 5.1. Corporate Social Responsibility, a new mechanism for the regulation of work? 5.2. Tools, new actors and debates on CSR. 5.3. Impact of CSR on the working conditions of workers. 6. Conclusions. 


\section{INTRODUCCIÓN}

En las últimas décadas, la globalización del sistema agroalimentario ha dado lugar al surgimiento, a lo largo y ancho del planeta, de nuevos enclaves de agricultura intensiva. Su orientación hacia mercados externos, su elevada modernización tecnológica y productiva y su intensa utilización de mano de obra, han convertido a la agroindustria en un sector que dota de dinamismo a los territorios en los que se asienta y convierte estos espacios en el escenario de intensos procesos de movilidad del trabajo y el capital. Este artículo pretende mostrar cómo, a pesar de la diversidad de contextos, podemos identificar en estos territorios un conjunto de convergencias globales, entre las que cabría destacar un uso intensivo del trabajo asalariado, unas relaciones de empleo que exigen una alta flexibilidad y una norma de producción regida por la discontinuidad temporal de los cultivos y, sobre todo, por las demandas cambiantes de los mercados.

La hipótesis que defendemos es que junto a estas convergencias, asistimos en estos espacios al surgimiento de nuevas formas de regulación transnacional, protagonizadas por las grandes empresas y cadenas de distribución, que están reconfigurando las relaciones de poder entre los diferentes agentes que intervienen en la regulación del trabajo. Para ello analizaremos, en primer lugar, la formación de cadenas globales de mercancías agroalimentarias, que incorporan nuevos territorios agroproductivos a lo largo y ancho de la economía-mundo, propiciadas por el régimen de acumulación flexible. A continuación, se describen las nuevas pautas de movilidad y asentamiento de la fuerza de trabajo que han contribuido a generar los nuevos enclaves de producción agrícola, en un contexto de incremento de los flujos migratorios locales y globales. En tercer lugar, se describe la nueva composición social del mercado de trabajo, mostrando su segmentación étnica y sexual, así como la precariedad de las condiciones de trabajo. Finalmente, se aborda la emergencia de nuevas formas y mecanismos de regulación transnacional de las condiciones laborales, estimuladas por el creciente poder de las grandes empresas y cadenas de distribución en la globalización agroalimentaria.

Las fundamentación empírica de este ejercicio exploratorio se sostiene sobre la numerosa bibliografía producida por investigadores en una amplia variedad de enclaves de agricultura intensiva y sobre el intercambio mantenido en la red de encuentro e intercambio que hemos tejido, en los últimos años, con numerosos colegas de Latinoamérica y del Sur de Europa en torno a la sociología de la agricultura y del trabajo jornalero, así como en numerosas visitas de campo realizadas a los territorios de la globalización agroalimentaria en México, Argentina, Ecuador y diversas zonas del sur de España.

\section{CADENAS GLOBALES AGRÍCOLAS: MOVILIDAD DEL TRABAJO Y DEL CAPITAL}

Fruto de una larga secuencia de profundas transformaciones históricas, la asociación de la agricultura y su lógica productiva con el proceso de sedentarización de los grupos humanos ha dado paso a otra imagen radicalmente diferente de aquella secular, que podríamos considerar incluso como su anverso, en la medida que la agricultura se vincula crecientemente con la movilidad del trabajo y del capital. ¿Cómo comprender este nuevo escenario sociohistórico de intensa movilidad que caracteriza hoy a la lógica de producción agraria y alimentaria?

En las ciencias sociales, una importante contribución teórica ha propuesto una explicación de la lógica global del capital a partir del concepto de cadenas de mercancías. ${ }^{2}$ Desde esta tradición se ha venido sistematizando un conjunto de características centrales de las redes globales de mercancías (Gereffi y Korzeniwicz, 1994; Gereffi, 1995) que pueden sintetizarse

\footnotetext{
${ }^{2}$ Este enfoque se asocia a la magna obra del sociólogo Inmanuel Wallerstein, quien fundamenta este concepto a partir de sus trabajos sobre la economía-mundo capitalista: "En la historia moderna, las fronteras reales dominantes de la economía-mundo capitalista se expandieron intensamente desde sus orígenes en el siglo XVI, de tal manera que hoy cubren toda la tierra... Una economíamundo está constituida por una red de procesos productivos intervinculados, que podemos denominar cadenas de mercancías, de tal forma que para cualquier proceso de producción en la cadena, hay cierto número de vínculos hacia delante y hacia atrás, de los cuales dependen el proceso en cuestión y las personas en él involucradas... En esa cadena de mercancías, articulada por lazos que se cruzan, la producción está basada en el principio de maximización de la acumulación de capital" (Wallerstein, 1979).
} 
en las siguientes: emergencia de un nuevo actor, la empresa transnacional, que define y constituye la movilidad prácticamente ilimitada y transfronteriza de los factores productivos; un conjunto interrelacionado de actividades económicas a partir del cual se produce la generación de valor; redes productivas y comerciales integradas por empresas de diversos tipos y tamaños y dispersas geográficamente; condiciones de posibilidad del funcionamiento de cada una de las fases de la cadena propiciadas por contextos institucionales; y finalmente, Estados nacionales a través de los cuales los territorios se insertan en las cadenas globales de mercancías.

La aplicación del concepto de cadena global de mercancías para entender las transformaciones agrarias contemporáneas ha tenido un importante recorrido en los estudios sociales agroalimentarios, que destacan dos modelos de estructuración de estas cadenas. Por un lado, las cadenas conformadas por las corporaciones transnacionales grandes e integradas verticalmente que internacionalizan aspectos de los procesos de producción, distribución y comercialización, las encontramos de forma predominante en los complejos de carne y de grasas/aceite (Friedmann y McMichael, 1989; Sanderson, 1986). Por otro lado, las cadenas conformadas por el capital comercial están marcadas por una mayor descentralización y fluidez, pues se trata de comerciales-compradores basados en empresas transnacionales, especializados en grandes cadenas de organización de la distribución comercial agroalimentaria, las cuales arman y mantienen relaciones con los productores que usualmente están localizados a lo largo y ancho de la economía-mundo, en territorios semi-periféricos o periféricos. Esta segunda forma la encontramos fundamentalmente en el subsector de frutas y hortalizas en fresco, bien analizada por Friedland y colaboradores para el caso californiano (Friedland, Barton y Thomas, 1981; Friedland, 1984, 1994 y 2001). No es casualidad que este desarrollo de la investigación haya sido propiciado desde California, pues fue en aquel territorio donde se desarrolló históricamente un modelo de agricultura fundamentado sobre una intensa concentración de capital, la movilización de importantes contingentes de mano de obra asalariada y una minuciosa racionalización productiva que posibilitó incrementos sustanciales en la escala de producción y circulación de frutas y hortalizas en fresco (Mc Williams, 1935; Fisher, 1953). Esta nueva globalización agroalimentaria vinculada a las frutas y hortalizas en fresco es el resultado de importantes transformaciones acaecidas en las últimas décadas. Por un lado, la demanda de productos frescos por una parte importante de la población y el acceso a los grandes mercados de países desarrollados ha dinamizado la actividad del sector y ha permitido tecnologizar los procesos productivos agrarios, alcanzando grados inimaginables de productividad y disminuyendo la estacionalidad, uno de los antiguos "males" en el proceso de industrialización de la actividad agrícola. Por otra parte, la expansión de la agricultura intensiva se ha basado principalmente en la creación de grandes y medianas empresas de explotación y en la asalarización del trabajo agrícola.

La estructuración de cadenas globales de mercancías en el subsector de frutas y hortalizas en fresco resulta el aspecto más novedoso de la nueva globalización agroalimentaria y ha conocido una enorme expansión territorial en América Central y del Sur, el Sudeste Asiático, Australia y Nueva Zelanda, países africanos como Sudáfrica y algunas regiones del Mediterráneo europeo. La proliferación de estas regiones agro-industriales aparece ligada a una nueva división internacional del trabajo en el marco de la reestructuración de la economía global (Sassen, 1988; 2001). El resultado de ello ha sido la configuración de un sistema global de frutas y hortalizas frescas en el que participan numerosos países de distintos continentes en una red mundial de producción y consumo, y en el que los países desarrollados son los principales consumidores y los países subdesarrollados son los principales productores (Friedland, 1994). No obstante, se trata de una división Norte/Sur que también se reproduce en el interior de la UE y en razón de la cual las regiones agroindustriales del Mediterráneo se han convertido en lo que se ha llamado la "huerta de Europa" (Pedreño, 2003 y 2005).

Las relaciones y jerarquías de poder no deben obviarse en ningún momento, pues son un elemento estructural de la morfología de la red. Una relación de poder central es la que se establece entre las grandes organizaciones de distribución centroeuropeas y los centros de producción, que acogen las tareas de cultivo y transformación, es decir, aquellas tareas más intensivas en trabajo y recursos naturales. De hecho, el desarrollo de este sistema agrario combina elementos internos y externos estructurados por posiciones de poder que, con Storper (1991), puede 
definirse como "endógeno, pero externamente orientado". Esta relación desigual entre una distribución globalizada y una producción localizada plantea continuamente incertidumbres de mercado para los productores (Segura y Pedreño, 2006: 413).

En esta era de movilidad del capital a través de las cadenas globales agroalimentarias, el territorio no solamente importa para la generación de valor sino que, además, cumple una función estratégica. Por ello, los territorios agroproductivos adquieren una peculiar morfología. Se asiste en los mismos a un proceso creciente de integración entre la producción, transformación y comercialización de alimentos en fresco, constituyendo un "conglomerado territorial" (Storper y Harrison, 1994) de numerosas y diferentes tipos de empresas, incluidas las proveedoras de medios de producción, de transformados vegetales, de manipulado del producto, etc., caracterizado por una alta concentración espacial, una intensa conexión entre sí sobre la base de relaciones de proximidad, un arraigo en estructuras de socialidad propias y con un entorno institucional que abarca desde instituciones políticas a centros especializados de investigación, pasando por un importante desarrollo del asociacionismo agrario.

La movilidad del capital y la movilidad del trabajo se articulan estrechamente en estos conglomerados territoriales. Para la gestión de ambas movilidades, y sus incertidumbres asociadas, se constituyen dos tipos de redes de empresas fundamentales, que afectan tanto a la división interna del trabajo como a su división externa. Por un lado, redes de clientes a través de contratos con las grandes cadenas de comercialización para afrontar la incertidumbre del mercado. Por otro lado, redes de reclutamiento de mano de obra para afrontar las incertidumbres del trabajo, las cuales han hecho del trabajador agrícola eventual una figura laboral esencial, tanto cuantitativamente -por las altas necesidades de fuerza de trabajo en aquellas partes del proceso de producción más intensivas en trabajo manual, fundamentalmente, las tareas propiamente de campo (recolección, plantación, etc.) y las líneas de confección y manipulado del producto-, como cualitativamente -por la exigencia de disponibilidad y adaptabilidad a una norma de producción regida por la discontinuidad temporal de los cultivos y por las demandas cambiantes de los mercados (plazos de entrega, calidades del producto, presentación del mismo, etc.).
Las empresas que protagonizan estos procesos muestran una organización flexible y horizontal, que se manifiesta en características tales como: organización en función del proceso y no de la tarea; evaluación de resultados por la satisfacción del cliente; descentralización productiva; formación de redes de producción "móviles" en el espacio regional, interregional e incluso transnacional a la búsqueda de ciclos anuales de producción; maximización de los contactos y del intercambio de información con los proveedores y clientes, etc.

Las nuevas formas de competitividad de esta modalidad de empresa-red del sistema global agroalimentario, particularmente en el subsector de las frutas y hortalizas en fresco, aparecen ligadas a una determinada geografía de la organización. Autores como Marsden (1997) y Friedland (1997, 2001) han conceptualizado la nueva lógica de organización global de la producción agrícola según los principios de jus-in-time, a partir de los cuales la producción se programa de "abajo a arriba" partiendo de los pedidos y de los productos ya vendidos (Coriat, 1993). Ello responde a la centralidad que adopta el consumo en la ordenación económica a través de la distribución comercial, la cual penetra profundamente en la producción, con disposiciones, normas y estándares que determinan las características de los productos y el modo en que éstos han de llegar a los mercados. Producir Justo-a-Tiempo y con calidad total implica introducir una precisión en la coordinación y sincronización de las diferentes fases de la producción en fresco. Todo esto genera una nueva realidad cuya complejidad organizacional ha sido con razón denominada "agricultura de precisión" (Watts y Goodman, 1997). Con ese concepto, se define una nueva lógica organizacional de la agricultura que supone una cuidadosa coordinación del conjunto de tareas que componen un proceso de trabajo internamente muy diferenciado y en el cual cualquier incidencia puede alterar la apariencia o características del producto.

En resumen, estos enclaves de producción comparten algunos rasgos a lo largo y ancho de la economía-mundo: desarrollan una actividad agrícola orientada a la exportación, se encuentran dominados por las grandes cadenas de distribución de los países desarrollados, están orientados a responder los nuevos hábitos alimentarios de las clases medias de los países desarrollados, registran un elevado grado de 
industrialización y de tecnologización de varias de las fases de los procesos productivos, y todo ello sobre la base de una intensa dinámica de concentración y centralización del capital. Estrechamente relacionado con esos procesos, se dan una serie de cambios en la composición social del trabajo agrícola según los cuales disminuyen considerablemente las relaciones basadas en el pequeño productor autónomo y sus relaciones familiares y adquieren una centralidad enorme las relaciones estructuradas sobre el trabajo asalariado. Como advierten las investigaciones sobre las nuevas regiones agroindustriales, el trabajador asalariado agrícola aparece como una figura social característica y en expansión en la globalización agroalimentaria, especialmente en aquellas producciones más intensivas en trabajo vivo (como es el caso de las frutas y hortalizas), siendo este rasgo fundamental en las convergencias globales detectadas.

Estas localidades y territorios agroproductivos generan una específica estructura de oportunidades, en forma de recursos ocupacionales u otros recursos sociales, que establece conexiones con las redes migratorias y de movilidad del trabajo. A través de las migraciones internas y transnacionales, las localidades agroexportadoras conocen un importante asentamiento de trabajadores agrícolas migrantes, y en ellas se conforma una específica socialidad, como se analizará en el siguiente apartado. Por otro lado, la agricultura de precisión se vincula con unas determinadas relaciones de empleo que exigen al trabajo una alta flexibilidad y disponibilidad que se reflejan en la forma del contrato y en la forma del salario, elementos estos que se abordarán en un apartado posterior.

\section{CIRCULACIONES MIGRATORIAS Y CONDICIONES DE VIDA JORNALERA EN LOS ENCLAVES DE AGRICULTURA INTENSIVA}

Las lógicas de reestructuración agrícola analizadas anteriormente han generado, como apuntábamos, una importante desterritorialización del trabajo por la vía del reclutamiento del mismo en mercados extralocales, y su consecuente reterritorialización en los nuevos campos de la globalización agroalimentaria. En estos espacios, donde la fuerza de trabajo local resulta insuficiente para responder a la intensa demanda de mano de obra que se genera en torno a la agricultura industrial, el funcionamiento de las cadenas globales depende, cada vez más, de su capacidad para movilizar trabajadores procedentes de otras regiones o países. Como las fábricas en los inicios de la industrialización, estas nuevas agroindustrias han tenido que responder al reto de movilizar mano de obra asalariada para fijarla a las producciones; pero a diferencia de aquéllas, en estas agriculturas intensivas la necesidad de fijar a los trabajadores se ha traducido, paradójicamente, no sólo en asentamiento sino también en una fuerte movilidad. Estos territorios agroalimentarios han desarrollado nuevas formas de producción y han generado nuevos circuitos de migración, lo que tiene como correlato la destrucción de las economías campesinas tradicionales y la alteración de las rutas migratorias tradicionales (Lara, 2005; Bendini y Steimbreger, 2010).

El patrón tradicional de movilidad, caracterizado por la migración pendular de campesinos pobres que se desplazaban a las zonas de producción agraria para abastecer las necesidades estacionales de mano de obra y después regresaban a sus localidades de origen, ha perdido protagonismo en las nuevas agriculturas intensivas. Tanto en América Latina como en el Sur de Europa, asistimos a una diversificación en los perfiles de estos nuevos jornaleros de la globalización, así como a una multiplicación de los circuitos migratorios. Como destaca Lara (2010), en la actualidad resulta cada vez más frecuente que los trabajadores agrícolas circulen por varios espacios productivos, en lugar de regresar a sus localidades de residencia, o que se instalen en alguno de estos lugares de trabajo para, desde allí, moverse hacia otros destinos.

Encontramos, por tanto, desplazamientos multipolares de población trabajadora y nuevas modalidades de ocupación del espacio rural (Lara, 2006), que convierten a los enclaves de agricultura intensiva en nuevos territorios circulatorios (Tarrius, 2000), en los que transitan diversos colectivos, con dinámicas de movilidad y asentamiento también diversas. ${ }^{3} \mathrm{La}$

\footnotetext{
${ }^{3}$ Para una aplicación del concepto de territorios circulatorios al estudio de las cadenas globales agrícolas, ver Lara (2010) y Sánchez y Saldaña (2009).
} 
organización de estos diferentes tipos de circulación se sostiene sobre "infraestructuras sociales" particulares, redes sociales y configuraciones familiares para la reproducción cotidiana que dan lugar a diferentes patrones migratorios y modelos de ocupación del territorio, así como a condiciones de vida y formas de relación social también diversos.

\subsection{Patrones de movilidad y condiciones de vida jornalera}

El trabajo asalariado en la agricultura se ha relacionado tradicionalmente con la estacionalidad de las producciones y la demanda de mano de obra puntual vinculada a determinados momentos del ciclo agrícola, que exigía el desplazamiento a las zonas agrícolas de importantes contingentes de trabajadores jornaleros. Estos desplazamientos, que articulaban diversas áreas geográficas pudiendo dar lugar a movimientos de tipo circular o pendular, se transforman en el marco de los procesos de reestructuración agrícola.

La migración estacional implica el desplazamiento de los trabajadores, de manera más o menos organizada, entre dos o más zonas agrícolas, para retornar al lugar de residencia, en origen o en alguna de las localidades de trabajo, aunque también encontramos formas extremas de nomadismo laboral (Pedreño, 1999), en la que los migrantes circulan entre distintos lugares de trabajo sin tener una residencia fija (Lara, 2006). La complejización de las migraciones circulares y pendulares puede ser entendida como una respuesta de los trabajadores a la reestructuración productiva en la agricultura, al menos en dos sentidos. De un lado, la crisis de la agricultura tradicional ha abocado a muchos pequeños campesinos a estrategias de proletarización en mercados de trabajo cada vez más flexibles, que implican forzosamente una gran movilidad como condición para su incorporación productiva. De otro, la deslocalización de la producción en diferentes regiones y la descentralización geográfica de las empresas, que encontramos en numerosos enclaves globales agrícolas, ha generado una mayor discontinuidad y dispersión territorial del empleo (Lara, 2010). Tampoco conviene subestimar el papel de los dispositivos políticos, como las políticas migratorias de cierre de fronteras o los acuerdos entre países para regular la contratación en origen, en la producción de esta movilidad permanente.
En este contexto, no sólo se complejizan los desplazamientos de los jornaleros, sino también sus patrones migratorios. En algunas zonas de América Latina, el predominio de la migración individual ha dado paso a una diversidad de situaciones: hombres y mujeres solas, grupos de parientes y paisanos, familias de campesinos indígenas y un conjunto diverso de configuraciones que se establecen específicamente para migrar (Grammont, Lara y Sánchez, 2003). En la vertiente mediterránea, los jornaleros autóctonos han sido sustituidos por trabajadores procedentes de las migraciones internacionales, que se desplazan a lo largo de todo el territorio español siguiendo las diferentes cosechas -cítricos en Valencia, frutales en Lérida y Aragón, aceituna en Jaén- o son reclutados para tareas agrícolas específicas, como la vendimia o la recogida de la fresa. Durante los años 80 y buena parte de los 90, estos desplazamientos estuvieron protagonizados principalmente por varones jóvenes, de origen magrebí y subsahariano; con la llegada del nuevo siglo, se ha producido una diversificación en los orígenes de estos jornaleros y se observa, además, una creciente presencia de mujeres y de familias de gitanos rumanos (Viruela, 2010).

La movilidad entre los diferentes espacios de agricultura intensiva se sostiene sobre las redes sociales que forman estos migrantes y, especialmente, sobre la figura de los enganchadores o capataces, que funcionan como estructuras de intermediación entre jornaleros y empleadores. En otros casos, el reclutamiento de mano de obra se organiza a partir de acuerdos entre diferentes regiones para la contratación en origen de trabajadores temporales.

Las migraciones circulares y pendulares, como estrategia de movilidad geográfica frente a la estacionalidad del trabajo agrícola, se revelan muy costosas en términos de condiciones de vida, de arraigo y de inserción social (Torres, 2002). Los migrantes que se desplazan de unas zonas agrícolas a otras son los que acumulan más situaciones de infravivienda, aunque encontramos variaciones significativas en función de los contextos, nacionales y regionales, y del modo en que los jornaleros son reclutados para trabajar en los campos. En algunos casos, los trabajadores improvisan campamentos en los campos de cultivo o en sus alrededores, construyendo habitaciones con materiales de desecho y sin ningún tipo de servicio, o se alojan en habitaciones alquiladas en 
los pueblos más cercanos. En otros, los empleadores proporcionan alojamiento a los jornaleros durante el periodo de cosecha, en instalaciones situadas en los campos agrícolas o cerca de ellos, espacios de vivienda que generalmente cuentan con equipamientos e infraestructuras insuficientes (Radonich, Steimbreger y Ozino, 1999; García Hidalgo, 2001; Sánchez y Saldaña, 2009; Saldaña, 2009; Lara, 2010; Reigada, 2011; Moreno, 2011). En ambos casos, las viviendas donde se alojan los temporeros suelen estar aisladas de los núcleos urbanos, lo que limita su acceso a los servicios y espacios públicos y, por tanto, los contactos con la población local. La segregación espacial refuerza las dinámicas de estigmatización desde las que se construye la imagen social de estos temporeros y los consolida, a la vez, como arquetipo del extraño y como encarnación moderna del vagabundo. Como figuras de alteridad y, más aún, de alteridad itinerante, se convierten en depositarios de diversos pánicos morales. A la ausencia de relaciones con la población local, los migrantes oponen una compleja trama de relaciones, a menudo dispersas geográficamente. Como señala Tarrius, la conformación de los territorios circulatorios y las movilidades que en ellos se generan son inseparables de las relaciones de solidaridad, pero también de clientelismo apuntamos nosotros, que los constituyen en espacios de intercambio, lo que genera "nuevas connivencias con nuevos otros, federados al colectivo circulatorio para transitar mejor, alcanzar mercados, empleos, sitios cada vez más lejanos" (Tarrius, 2000:57).

\subsection{Asentamiento de migrantes, segregación y convivencia socio-espacial}

Si los enclaves con producciones estacionales han dado respuesta a la demanda puntual de mano de obra mediante la movilización de trabajadores a través de la migración circular y pendular, en las zonas de agricultura intensiva donde se ha dado una desestacionalización de la producción con la diversificación de los cultivos encontramos, además, un patrón de migración que ha tendido al asentamiento de los migrantes. En estos espacios la necesidad continua de fuerza de trabajo, el aumento y la estabilización del empleo, las oportunidades de trabajo en sectores no agrícolas y, en el caso de trabajadores extranjeros, los procesos de regularización y de reagrupación familiar, contribuyen a fijar espacial- mente a estos nuevos jornaleros. En el asentamiento de estos migrantes podemos constatar una diversidad de situaciones, que van desde la segregación socio-espacial a la convivencia residencial, más o menos normalizada aunque no exenta de problemas (Torres, 2002).

Las colonias de mexicanos en los valles agrícolas de California durante la primera mitad del siglo XX (Palerm, 1999; 2010) o la situación de los inmigrantes africanos en las zonas de agricultura intensiva de Almería y Murcia durante los años 80 y 90 (Martínez Veiga, 2001; Checa y Arjona, 2007; Río, 2002; Torres, 2007) constituyen ejemplos de ese modelo de asentamiento que hemos calificado de segregación socio-espacial. En ambos casos, salvando las distancias geográficas y temporales, encontramos una situación marcada por la precariedad residencial, a menudo en condiciones de infravivienda, y la separación física y social de los jornaleros, excluidos de los espacios y servicios públicos de los núcleos urbanos y de las relaciones con la población local. En este modelo de inserción residencial, se observan dinámicas similares a las descritas para la movilidad estacional y diversas estrategias de cierre étnico que pretenden una segregación completa entre autóctonos e inmigrantes.

Frente a este modelo, y a veces como resultado de su evolución o en coincidencia con él, encontramos un patrón de asentamiento que podemos calificar de convivencia normalizada. En estos casos, la instalación de los jornaleros en los pueblos y ciudades se traduce en una co-presencia residencial y genera espacios comunes de sociabilidad cotidiana (Torres, 2009). El establecimiento de estos migrantes, internos o internacionales, suele seguir pautas de distribución desigual, no sólo en relación con la población autóctona, sino también entre los diferentes colectivos, que se concentran en determinados espacios siguiendo líneas de estratificación, de clase o étnica, previas (Torres, 2009). Se configuran, así, barrios de concentración inmigrante, como efecto de las redes y cadenas migratorias y de la dinámicas de sustitución étnica que implican una "huída" de la población autóctona (Palerm, 2010; Torres, 2007). Su instalación conlleva, generalmente, una apropiación y resignificación de determinados espacios, con la creación de comercios étnicos y de lugares donde estos jornaleros desarrollan prácticas religiosas, lúdicas y culturales (Sassone, 2007). Junto a estas for- 
mas de sociabilidad etnificada, encontramos en ocasiones un asociacionismo propio a través del cual se reivindican derechos, se reafirman identidades distintivas, se demanda reconocimiento y se mantienen vínculos con las localidades de origen (Velasco, 2002; Pizarro, 2009; Gadea y Albert, 2011). La co-presencia residencial establece, en la mayoría de casos, dinámicas de convivencia pacífica, en la que no se dan tensiones especialmente importantes ni relaciones significativas entre vecinos de distintos orígenes (Torres, 2009), aunque también se constatan dinámicas más excluyentes, de discriminación en el acceso a determinados espacios o servicios e, incluso, de conflicto étnico (Río, 2002). Los nuevos enclaves de agricultura intensiva se constituyen, así, en espacios de alta densidad relacional, lugares de encuentros y desencuentros, donde se movilizan solidaridades y cierres étnicos (Lara, 2011).

La creciente etnificación de los mercados de trabajo agrícola se manifiesta, como hemos visto, en distintas formas de segregación, vulnerabilidad social y precarización de las condiciones de vida y de trabajo de los migrantes. Algo que, además, se extiende al conjunto de las relaciones sociales. En este sentido, podemos hablar de sociedades etnofragmentadas (Pedreño, 2005), en las que sobre la base de la etnicidad, se redibujan las diferenciaciones y jerarquías de género y clase (Pedreño y Riquelme, 2006). En consecuencia, la problemática del inmigrante en los enclaves de agricultura intensiva y en las zonas rurales no es una problemática de exclusión, sino de vulnerabilidad y explotación laboral a través de la precariedad (Pedreño y Riquelme, 2006). De ahí que en el siguiente apartado se analicen las condiciones precarias del trabajo agrícola así como la nueva composición social del mercado de trabajo agrícola.

\section{CONVERGENCIAS Y DIVERGENCIAS DE LAS LÓGICAS DE EMPLEO Y CONDICIONES DE TRABAJO}

Una de las tendencias que encontramos en las cadenas globales de producción agrícola es la exigencia de disponibilidad y adaptabilidad a una norma de producción regida por la discontinuidad temporal de los cultivos y por las demandas cambiantes de los mercados, lo que se ha traducido en unas re- laciones de empleo que exigen al trabajo una alta flexibilidad.

El funcionamiento óptimo y la competitividad de los enclaves de agricultura intensiva dependen, por tanto, de la disponibilidad de fuerza de trabajo flexible y móvil, de la producción y reproducción de sujetos sociales vulnerables que se muestren disponibles para ocupar los puestos de un mercado de trabajo cada vez más precarizado. De ahí que sea decisivo prestar atención a sus principales rasgos, así como a los factores que intervienen en su configuración. Por otra parte, la profunda reestructuración de la producción agroalimentaria se sostiene sobre una sofisticada organización del trabajo. La llamada "taylorización" de los procesos productivos agrarios ha endurecido significativamente las condiciones del trabajo agrícola. Considerada como una estrategia orientada a responder con agilidad a la demanda, la creciente coordinación entre las diferentes fases productivas se traduce en un incremento de la adaptabilidad y de la flexibilidad de los trabajadores en varios sentidos: flexibilidad salarial (contención salarial y salario a destajo), flexibilidad horaria (prolongación e intensificación de la jornada), flexibilidad funcional (realización de múltiples tareas no especializadas), flexibilidad geográfica (movilidad entre diferentes territorios). Unas exigencias de flexibilidad que, en este caso, han contribuido a empeorar significativamente las condiciones de trabajo agrícola y que han recaído sobre los grupos sociales más vulnerables.

\subsection{La constitución de los mercados de trabajo agrícola y la nueva estructura social jornalera}

En efecto, numerosos estudios sobre estos enclaves muestran que han sido los inmigrantes y las mujeres locales los sujetos sociales que se han constituido en trabajadores asalariados agrícolas (Segura et al, 2002; Cavalcanti et al, 2002; Lara 2011). En cuanto a las mujeres, éstas tienen una presencia importante en el mercado de trabajo de los enclaves de agricultura intensiva. Una presencia que varía en cada fase del trabajo agrícola y en cada enclave. Además, aunque la participación de las mujeres en la agricultura sigue considerándose ampliamente como una ayuda familiar, algo que sirve para justificar una remuneración menor, también se está produciendo 
una tendencia hacia la profesionalización, sobre todo entre las mujeres inmigrantes. Por otra parte, persisten las pautas de desigualdad entre hombres y mujeres en la medida en que las mujeres ocupan trabajos manuales y semicualificados que son más inestables y peor remunerados que los de los hombres. Por último, esta desigual división sexual del trabajo reproduce y naturaliza los roles tradicionales de género, señalando que las tareas más delicadas son propias de las mujeres y que tanto las tareas más físicas como las tareas de gestión son propias de hombres (Reigada, 2010).

Por su parte, los trabajadores procedentes de las migraciones interiores y exteriores también forman parte de la nueva composición social de los enclaves de agricultura intensiva. En el caso de las zonas agroexportadoras mediterráneas, los trabajadores inmigrantes proceden principalmente de América Latina, de los países del Magreb occidental y de los países del Este (Alzamora et al, 2010). Este espectacular incremento de los flujos migratorios hacia las zonas del Mediterráneo ha permitido "anegar" el mercado de trabajo agrícola y dar lugar a una etnificación del trabajo agrícola (Pedreño, 2005). La magnitud de este verdadero "ejército de reserva" ha contribuido a generar una ingente bolsa de mano de obra desocupada que ha sido instrumentalizada por las empresas para desplegar agresivas estrategias de reclutamiento y de sustitución de mano de obra, consiguiendo así una reducción de costes laborales que se ha constituido en el núcleo de la competitividad del sector en los mercados globales.

Por último, otra pauta común en los mercados de trabajo de los enclaves de agricultura intensiva es la vulnerabilidad económica, social y política, de los trabajadores agrícolas (sobre todo, de los trabajadores inmigrantes). La posición vulnerable de los inmigrantes en el mercado de trabajo de las áreas de la agricultura intensiva del Mediterráneo, por ejemplo, se deriva de la precaria condición de ciudadanía sobredeterminada por los dispositivos de gestión de la extranjería, los cuales condicionan el permiso de residencia a la posesión de un contrato de trabajo, otorgando así un poder desmesurado al empleador, y que, en razón del criterio de preferencia nacional, restringe las ocupaciones a las que pueden acceder los inmigrantes (García y Pedreño, 2002). Mientras que en el caso de las mujeres locales, su vulnerabilidad social y económica se debe principalmente a su inserción en estructuras familiares en las que aún sigue vigente una distribución tradicional de los roles de género, en razón de la cual su trabajo se considera una ayuda familiar y una actividad no cualificada, consideraciones ambas que legitiman un menor reconocimiento económico de su actividad laboral (Castellanos y Pedreño, 2001; Candela y Piñón, 2005)

Sólo en un contexto institucional y cultural que produce este tipo de sujetos sociales vulnerables social y políticamente es posible poner en funcionamiento estrategias empresariales como las de regularización parcial de la prestación laboral, las de contratación en origen y las de sustitución étnica. Además, es este contexto uno de los principales factores que contribuye a generar la predisposición a la flexibilidad de los trabajadores para adaptarse a unas condiciones de trabajo que han empeorado significativamente a pesar de la modernización tecnológica de la producción agraria.

\subsection{La paradoja de la modernización tec- nológica de los procesos productivos y de la precarización de las condiciones de trabajo}

A pesar de la modernización tecnológica de sus procesos productivos, la agricultura industrial sigue siendo muy intensiva en el uso de mano de obra, de ahí que se haya convertido en un importante factor en la creación de empleo. Paradójicamente, el aumento del tamaño de las empresas y, por tanto, de la escala de sus explotaciones agrarias, la modernización tecnológica, el aumento de la productividad y el elevado grado desestacionalización, no han dado lugar a la creación de empleo estable y de calidad sino, más bien, a una mayor precariedad de las relaciones de empleo y de las condiciones de trabajo. Esta paradoja sólo puede comprenderse como un elemento más dentro de una estrategia empresarial de competitividad para insertarse en los mercados globales basada en la reducción de costes laborales. Estrategia que es desarrollada para no debilitar el margen de beneficios, dada la relación de subordinación con respecto a las grandes empresas de distribución, y para reducir la probabilidad de aparición de conflictos laborales debilitando la posición negociadora de los trabajadores agrícolas (Segura et al, 2002; Pedreño, 2003). 
A continuación, describiremos las principales pautas $^{4}$ comunes de las condiciones de trabajo y de empleo en los enclaves de la agricultura intensiva que se derivan de determinados contextos legislativos y de determinadas estrategias empresariales: principalmente, empleo inestable y condiciones precarias de trabajo. Estas condiciones de trabajo suponen, como veremos, un claro debilitamiento de los mecanismos de negociación colectiva y van a permitir el surgimiento de nuevas formas de regulación.

\section{A) Inestabilidad en el empleo}

Las situaciones contractuales de los trabajadores en los enclaves de la agricultura intensiva son muy heterogéneas. Sin embargo, una de las características comunes y más reconocibles de estos enclaves es el predominio de una nueva composición de la fuerza y del mercado de trabajo, gestionada principalmente por medio de relaciones contractuales de carácter eventual (Sánchez, 2006, 2011; Lara, 2008, 2011; Segura et al, 2002; Martin, 2002; Castellanos y Pedreño, 2001). Aunque pueda haber crecido una minoría de trabajadores estables, la mayoría ve reguladas sus condiciones de empleo por la vía de la eventualidad. Los trabajadores eventuales pueden llegar a firmar varios contratos temporales a lo largo del año. Aunque varía en cada área geográfica, gracias al encadenamiento de campañas basado en la sucesión escalonada y en las rotaciones de los ciclos de cultivo, los trabajadores agrícolas pueden llegar a trabajar entre 6 y 10 meses al año (Lara, 2008; CES, 2001).

No obstante, la situación más extendida en estos enclaves agrícolas es la del trabajo sumergido o informal. Se trata de una situación que es difícilmente mensurable debido a su ocultamiento. Según una encuesta realizada en el año 2000 a 204 trabajadores agrícolas en uno de los más importantes enclaves de la agricultura intensiva en Europa, trabajaban sin contrato el $83,1 \%$ de los trabajadores inmigrantes en situación ilegal y el $24,8 \%$ de los que estaban en situación legal (CES, 2001: 450).

Otra pauta común observable en las condiciones laborales en estos enclaves es la externalización de la gestión de las relaciones laborales por parte de las empresas. Los empresarios tienden a desentenderse cada vez más de las formas de reclutamiento de la mano de obra y de los sistemas de remuneración gracias a la figura del intermediario, que en sus variadas modalidades cabe encontrarla en una diversidad de contextos (Sánchez, 2006; Pedreño, 1999). El intermediario puede ser una empresa de trabajo temporal o un contratista individual de mano de obra o una cuadrilla (aunque gestionada por un contratista). La función principal de los intermediarios consiste en coordinar espacial y temporalmente la oferta y la demanda del mercado de trabajo. Se trata de una función crucial en un sector en el que, a pesar de la atenuación de la estacionalidad, la necesidad de mano de obra sigue siendo fluctuante. Los intermediarios garantizan el suministro estable y puntual de mano de obra y un coste reducido. La empresa paga una cantidad global por el trabajo de un determinado número de trabajadores durante un periodo de tiempo determinado y en un campo concreto. No establece así ninguna relación jurídica con el trabajador sino con el intermediario, quien se hace responsable de la situación legal de los trabajadores.

En resumen, la característica más llamativa en todos estos enclaves es que la proporción de trabajadores contratados directamente por la empresa es muy reducida si se tiene en cuenta que una buena parte de ellos son contratados por intermediarios y otra parte trabajan sin contrato.

\footnotetext{
${ }^{4}$ La organización de estas pautas se apoya parcialmente en las principales características que la Organización Internacional del Trabajo (OIT) ha distinguido para medir el "trabajo decente". El Programa del Trabajo Decente de la OIT pretende evaluar las realidades del trabajo a nivel global y pretende fomentar su materialización instando a las instituciones nacionales y supranacionales a incluir en su agenda los siguientes objetivos: crear trabajo, garantizar los derechos de los trabajadores, extender la protección social y promover el diálogo social (Anker et al., 2003; Ghai, 2003). Véase también: http://www.ilo.org/global/about-the-ilo/decent-workagenda/lang--es/index.htm. Las seis facetas del trabajo decente son: oportunidades de trabajo, trabajo en condiciones de libertad, trabajo productivo, equidad en el trabajo, seguridad laboral y dignidad laboral. Anker et al. (2003) concretan las seis facetas anteriores en once categorías con el objetivo de medir el trabajo decente: Oportunidades de empleo, trabajo inadmisible, remuneración, jornada laboral, estabilidad y seguridad del empleo, conciliación del trabajo con la vida familiar, trato justo en el trabajo, salud, seguridad e higiene en el trabajo, protección social, y diálogo social y relaciones laborales (Anker et al., 2003: 168-9).
} 
B) Precariedad de las condiciones de trabajo: salarios bajos, jornadas largas y la salud en peligro

Según numerosos estudios sobre los enclaves de la agricultura intensiva, puede señalarse que los salarios son, por término medio, menores que en otros sectores de actividad. ${ }^{5}$ Cuando existe convenio, éste suele reflejar un salario mínimo bajo y tiende a respetarse (Avellá y Vega, 2002; Martin, E. 2002; Segura et al, 2002; Candela y Piñón, 2005). Además, hay que destacar que en estos enclaves los intermediarios suelen apropiarse de una parte de los salarios que pagan las empresas por diferentes conceptos (gastos de intermediación, transporte, alimentación, alojamiento) (Pedreño, 1998; CES, 2001; Lara, 2010; Sánchez, 2006). Por otra parte, hay que destacar que el sistema de retribución salarial más frecuente en estos enclaves es el salario por horas (CES, 2001; Lara, 2011), lo que supone que en el caso de que la jornada se vea reducida por circunstancias climáticas o cualesquiera otras, la remuneración se verá reducida igualmente.

Por otro lado, una de las consecuencias de la mecanización de las fases del ciclo productivo agrícola ha sido la extensión de las jornadas, así como la intensificación de los tiempos de trabajo mediante la incorporación de técnicas organizacionales de carácter fordista y taylorista. (Avellá y Vega, 2002; Martin, 2002; Segura et al, 2002; Candela y Piñón, 2005, Lara, 2011). Es difícil determinar con exactitud la duración efectiva de las jornadas de trabajo en estos enclaves. No obstante puede estimarse que sean de más de 8 horas porque los trabajadores necesitan aprovechar los periodos de máxima actividad para compensar con un incremento de salario los meses que no trabajan y por la propia necesidad de los empresarios de llevar a término lo más rápido posible las campañas de recogida para comercializar sus productos, lo que actúa como un factor esencial de intensificación del trabajo. La encuesta citada anteriormente parece corroborar estas estimaciones al señalar que el $62 \%$ de los trabajadores tiene una jornada de entre 9 y 10 horas (CES, 2001: 453; Lara, 2008). Por otra parte, se trata de una jornada que aumenta debido a los largos desplazamientos que han de realizar los trabajadores para llegar a la explotación agraria.

Por último, la salud de los trabajadores se encuentra sometida a importantes riesgos en estos enclaves. En este sentido, Bilbao vinculaba los problemas de salud laboral con las condiciones del entorno de trabajo. Señalaba que las afecciones físicas y psicológicas no son más que "el final visible de una sucesión de acontecimientos que describen un entorno penoso para determinados individuos" (Bilbao, 1997). La sucesión de acontecimientos para la mayoría de los trabajadores agrícolas son la prolongación e intensificación de las jornadas de trabajo en periodos de máxima actividad, los movimientos monótonos y repetitivos que requieren casi todas las tareas, la repetición de posturas de alto riesgo (estar siempre de pie o estar siempre agachado o en cuclillas), el trabajo al aire libre a temperaturas extremas o en centros de trabajo con alto grado de humedad, poco ventilados, etc. Estos son, por tanto, los "acontecimientos" que constituyen el entorno de trabajo en los enclaves de la agricultura intensiva y que son los responsables de dolencias crónicas, afecciones y enfermedades (Martín, 2002; Candela y Piñón, 2005). Por otra parte, los desplazamientos que tienen que realizar los trabajadores también constituyen una fuente de riesgo laboral, ya que éstos no suelen hacerse bajo condiciones de seguridad (sobrecarga, exceso de velocidad, carreteras secundarias) por lo que los accidentes se han convertido en una rutina en estos contextos productivos.

En resumen, la temporalidad de los contratos, la informalización de las relaciones laborales y la creciente ruptura del vínculo directo entre trabajadores y empresarios dificultan que se desarrollen mecanismos de negociación colectiva de ahí que predomine la gestión individualizada de los conflictos, situación en la que el poder de negociación de los trabajadores es muy débil. Una debilidad negociadora aún mayor si se toma en consideración que la mayoría de los trabajadores agrícolas son inmigrantes y que su situación legal les hace aún más vulnerables en términos jurídicos.

${ }^{5}$ Véase, por ejemplo, este estudio de EUROFOUND http://www.eurofound.europa.eu/eiro/2005/09/study/tn0509101s.htm. 


\section{5. ¿HACIA UNA REGULACIÓN TRANSNACIONAL DE LOS DERECHOS DE LOS TRABAJADORES Y TRABAJADORAS EN LA AGRICULTURA?}

El análisis de las convergencias globales en los enclaves de agricultura intensiva que hemos realizado en los apartados anteriores muestra cómo la globalización agroalimentaria se ha sostenido sobre la creciente precarización de las condiciones de vida y trabajo de los jornaleros agrícolas que se ocupan en estos enclaves. Las estrategias ${ }^{6}$ de des-regulación y re-regulación de las actividades productivas $\mathrm{y}$, en particular, de las relaciones laborales (Aparicio, 1997; Baylos, 1999) que acompañan la internacionalización de la economía y la integración financiera y comercial a nivel mundial han jugado un papel fundamental en estos procesos.

En un contexto de deterioro de las condiciones de trabajo, y de la posición negociadora de los trabajadores, se están desarrollando nuevas formas de regulación de las relaciones laborales que se caracterizan por su vocación transnacional y porque proceden, en la mayoría de casos, de actores privados al margen del estado. Como ha señalado Pries (2008) existe en la actualidad una "textura de redes emergente de regulación laboral internacional" constituida por diversos tipos de internacionalización. Dan cuenta de ello los estándares mínimos laborales propuestos por la OIT, las múltiples directrices de la Unión Europea sobre cuestiones laborales, los convenios de la OIT sobre trabajadores migrantes y las recomendaciones que les sucedieron. ${ }^{7}$ Han surgido también distintas normativas para la regulación de las actividades de las compañías transnacionales o de aquellas empresas que deslocalizan su producción o que mantienen relaciones comerciales en distintos países. Es en esta dimensión internacional y transnacional de la regulación de los derechos de los trabajadores en la que centraremos nuestra atención en las siguientes páginas. Nos interesa, especialmente, la regulación transnacional promovida a través de los códigos de conducta y de los Acuerdos Marco Globales, iniciativas todas ellas vinculadas a lo que se ha dado en llamar la Responsabilidad Social Empresarial (RSE). Para ello, analizaremos qué características tiene este espacio emergente de regulación transnacional laboral, en qué marcos normativos se sustenta, de qué instrumentos se vale y cuál es el papel de los distintos agentes en su configuración.

\section{1. ¿La Responsabilidad Social Empresarial como mecanismo de regulación laboral?}

La economía del nuevo orden global ha trastocado elementos esenciales de la regulación jurídica de las relaciones laborales (Baylos, 2009). La diversificación de los campos de la regulación ha propiciado en las últimas décadas la emergencia de un nuevo tipo de regulación del trabajo promovido a partir de las iniciativas de responsabilidad social empresarial (RSE). La influencia de la RSE sobre las condiciones laborales está adquiriendo un gran relevancia en la actualidad y es esperable que su influencia sea cada vez mayor teniendo en cuenta la promoción que se está haciendo de estas iniciativas desde diversos ámbitos. Los debates sobre la RSE no están desligados de las transformaciones en la organización productiva y del trabajo de las empresas en el sistema de acumulación flexible y la centralidad que comienza a adquirir el consumidor en la ordenación económica. Los principales debates surgen en la década de los setenta a partir de la reacción de empresas multinacionales ante las repercusiones negativas de las acciones que estaban llevando a cabo en aquellos países a donde trasladaban parte de su proceso productivo. En su origen estas iniciativas deben interpretarse como estrategias para mejorar la imagen pública de las empresas ante la repercusión negativa, entre sus consumidores y la sociedad en general, de las condiciones de trabajo en las que se llevaba a cabo su producción. El proceso creciente

\footnotetext{
${ }^{6}$ Estrategias promovidas tanto por los estados nacionales como por organizaciones supranacionales (Unión Europea) e internacionales (FMI, OMC), y presentadas todas ellas en el marco de políticas de flexibilidad consideradas necesarias para adaptar las economías nacionales a la creciente competitividad mundial. Estrategias que podemos vincular con la búsqueda de dotar al sistema global de una nueva gobernabilidad (Sassen, 2010).

${ }^{7}$ Ejemplos de estos instrumentos de regulación internacional son la declaración de la OIT sobre los principios y derechos de los trabajadores 1998, la creación de los comités de empresa europeos, los convenios $n^{\circ} 97$ (1949) y n 143 de la OIT (1975) sobre trabajadores migrantes o las recomendaciones $\mathrm{n}^{\circ} 100$ (1955) y $\mathrm{n}^{\circ} 151$ (1975) de la OIT sobre trabajadores migrantes.
} 
de adopción por parte de las empresas de la RSE puede interpretarse, por tanto, como una estrategia de marketing con el objetivo de lograr ventajas comparativas y satisfacer las demandas de un consumidor posmoderno cada vez más exigente y que reclama calidad y sostenibilidad. Por otra parte, desde la dimensión laboral de la RSE, puede entenderse como una estrategia que permite atenuar los conflictos laborales internos y que a la postre contribuye a la despolitización de la regulación de las relaciones laborales (Baylos, 1999).

Sin embargo, la responsabilidad social empresarial es todavía hoy un concepto poco claro. No existe un consenso sobre su significado entre los distintos organismos internacionales o supranacionales, ni tampoco entre las empresas que dicen llevarla a cabo. En el Libro Verde, que representa la primera iniciativa a escala europea de promoción de la RSE, se la define como "la integración voluntaria, por parte de las empresas, de las preocupaciones sociales y medioambientales en sus operaciones comerciales y sus relaciones con sus interlocutores" (Libro Verde, 2001). En su dimensión laboral la RSE implica aspectos variados que van desde el respeto a los derechos básicos de los trabajadores promovidos por la OIT hasta aspectos relacionados con la formación y la conciliación laboral. La Unión Europea comienza en el año 2000 a hacer un llamamiento al fomento de la responsabilidad social de las empresas y a buscar un marco europeo que la promueva. En España tanto su marco jurídico como su implantación en las empresas españolas es relativamente reciente y aún embrionario (Aragón, Rocha y Cruces, 2005). Sin embargo, desde el año 2004 a nivel estatal se comienzan promover distintas iniciativas vinculadas a la estrategia europea de fomento de la RSE. El Estado, por tanto, comienza a desarrollar en este período una serie de iniciativas a través de las cuales se fomenta la incorporación de estos nuevos marcos regulatorios privados que a la vez que privatizan la autoridad, debilitan la responsabilidad pública del Estado sobre la regulación laboral. En el caso español, a partir del 2004 el gobierno se propone desarrollar una política de fomento de la responsabilidad empresarial en la que destaca partir del principio de voluntariedad de estas prácticas y de complemento a las normas legales. En materia laboral establece que la RSE debería incidir en aspectos relacionados con la igualdad de género, la conciliación, la reducción de la precariedad en el empleo, la formación continua y la prevención de riesgos laborales (Ministerio de Trabajo, 2008).

Hasta el momento las iniciativas promovidas en el marco de la RSE se caracterizan en primer lugar por su carácter voluntario, lo cual quiere decir que son normas que no tienen un carácter vinculante. En segundo lugar, por la privatización del proceso de elaboración de normas que estas iniciativas suponen (Sassen, 2010) en el que tienen un papel sustancial nuevos actores como la empresa transnacional y diversos agentes privados de certificación y control. Aspectos que llevan a reflexionar sobre las implicaciones que trae consigo este nuevo tipo de regulación en lo que refiere específicamente a los derechos de los trabajadores. Es decir, ¿qué efectos tiene el criterio de voluntariedad que domina en la mayoría de enfoques y propuestas de este tipo y qué consecuencias introduce la misma en la regulación de las relaciones laborales? Y al mismo tiempo, ¿quién ejerce el control y la verificación de las medidas de responsabilidad social que las empresas dicen estar desarrollando? Reflexionaremos sobre estas cuestiones mientras analizamos los principales instrumentos de estas políticas y el papel que juegan nuevos actores privados en estas acciones.

\subsection{Instrumentos, nuevos actores y debates sobre la RSE}

Dos de los principales instrumentos en el desarrollo de las políticas de RSE son los códigos de conducta y los acuerdos marco globales o también llamados pactos globales. Esto últimos se presentan como un paso más allá en la creación de mecanismos específicos de responsabilidad social y buscan superar algunas de las principales deficiencias que caracterizaban a las primeras y mayoritarias iniciativas que estaban siendo desarrolladas.

Los códigos de conducta son uno de los primeros instrumentos creados por las empresas en el marco de sus políticas de responsabilidad social. En muchos de éstos se incorporan aspectos vinculados a las condiciones de trabajo y se hace mención al respeto de los estándares mínimos establecidos por la OIT. Sin embargo, una de las principales críticas que se ha hecho a estos instrumentos es la unilateralidad que se sustentaba bajo el principio de voluntariedad, unilateralidad tanto en el diseño como en el segui- 
miento y verificación del cumplimiento de los mismos (Cefreda, 2005).

Con la aparición de los códigos de conducta emergen también nuevos actores privados encargados de elaborar las normas y los estándares de responsabilidad social así como de verificar su cumplimiento. Muchos de éstos creados o financiados por las propias empresas para desarrollar los procesos de control, al mismo tiempo que como nuevos mecanismos y normas de medición y acreditación. La Global Reporting Initiative (GRI), propuesta por las Naciones Unidas, es actualmente el referente para la elaboración de informes de sostenibilidad. En el ámbito de las ONG, La Plataforma de la Iniciativa para la Agricultura Sostenible (Sustainable Agriculture Initiative Platform), Sustainable Food Laboratory y la Iniciativa de Comercio Ético (Ethical Trading Initiative) son algunas de las más importantes tendencias en el sector agroalimentario. Sin embargo, algunas empresas confeccionan sus propios sistemas de verificación. $\mathrm{Y}$ en algunos sectores tienen mayor relevancia distintos tipos específicos de sistemas. Por ejemplo, en el sector de frutas y hortalizas se requiere fundamentalmente seguir los criterios de BSCI, SEDEX, GlobalGAP entre otros. Los debates y las críticas recibidas por los códigos de conducta han hecho que en los últimos años hayan despertado mayor interés los Acuerdos marco globales, en los que se ha incorporado la participación sindical y las organizaciones de trabajadores han buscado transformar a través de éstos las reglas informales de la empresa características de los códigos de conducta a una formalidad contractual. Incorporan figuras de autonomía colectiva y de representación sindical donde solo había autoridad privada.

Los acuerdo marco globales son pactos firmados por la Federación sindical internacional del sector y los comités de empresa europeos de la misma. Conforman, así, acuerdos marco sectoriales. Las políticas de RSE vinculadas a los acuerdo marco globales incluyen una dimensión interna y externa porque alcanzan también a proveedores y subcontratas. En estos acuerdos se establecen compromisos de obligatoriedad de cumplimiento y se comprometen a no entablar o mantener relaciones comerciales con proveedores o empresas subcontratadas que no respeten las normas contenidas en el acuerdo. En general los acuerdos incluyen el respeto a las normas de la OIT aunque algunos incluyen otras aspectos como la for- ma de relacionarse con los poderes públicos y autoridades de los Estados donde se instala la empresa transnacional, una conducta pública como no mantener complicidad con la violación de los derechos humanos y no fomentar prácticas de corrupción (Baylos, 2009). A junio de 2008, sesenta y tres empresas y grupos empresariales habían suscrito un acuerdo marco global. En la esfera de la alimentación se pueden citar Fonterra-IUF (2002), Chiquita-IUF (2001), Carrefour-UNI (2001) y Danone-IUF (1988).

Según Merino "en cuanto a su eficacia jurídica, no cabe duda de que su naturaleza consensuada permite inscribir a estos Pactos en el marco de una negociación colectiva transnacional, desprovista, sin embargo, de eficacia normativa, pero negociación colectiva al fin y al cabo" (2005:22). Sin embargo no todos los autores piensan lo mismo. La cuestión es que los mecanismos de puesta en práctica y el control del cumplimiento del acuerdo marco global se traducen en una serie de procedimientos de carácter voluntario. Información, en primer lugar, a trabajadores y a toda la cadena de producción (contratistas, proveedores) $\mathrm{y}$, en segundo, a los representantes de los terceros países sobre el acuerdo. Como señala Baylos (2009) “parece una obligación de fácil cumplimiento" pero no es así, ya que se da por supuesto que en todo lugar donde se localiza la empresa transnacional existe un sujeto representativo de los trabajadores concernidos por el acuerdo marco global. Las situaciones de debilidad sindical dificultarían la circulación de la información. Sus instrumentos de control son superiores a los de los Códigos, ya que suelen recoger reuniones anuales o semestrales en las que participan los responsables de las organizaciones firmantes de los distintos países, lo que para la acción sindical sí es importante ya que desde la perspectiva jurídica incluyendo las diferentes formas de autotutela sindical, sigue siendo una regulación muy insuficiente. Hernández (2009) llama la atención sobre la escasa legitimidad y credibilidad de algunas de las iniciativas de verificación llevadas a cabo por las consultoras privadas u ONG ya que "la privatización y el monopolio de las empresas que se dedican al mismo son perfectamente verificables". 


\subsection{Impacto de la RSE en las condiciones laborales de los trabajadores}

Como hemos mostrado, las políticas de RSE se vienen incrementando en los últimos años y cada vez son más las empresas que promueven códigos de conducta y acuerdos marco globales o que exigen a sus socios y proveedores cumplir con las normas vinculados a éstos. Sin embargo, más allá de esta retórica de la responsabilidad social ¿qué impacto tienen estas iniciativas en las condiciones laborales de los trabajadores? Como señala Korovkin y Sanmiguel-Valderrama (2007:18) "los códigos de conducta suelen ser ambiguos y son frecuentemente publicitados entre los consumidores del Norte más que entre los trabajadores locales".

Para analizar el impacto de las políticas de RSE vamos a presentar un caso concreto en la industria agroalimentaria: la empresa "Chiquita" de la industria bananera. La empresa "Chiquita" es una multinacional que exporta bananos desde distintas partes de América Latina. Esta empresa estableció un acuerdo marco global en el año 2001 y posee su propio sistema de certificación. Prieto-Carrón (2006) muestra el impacto de las medidas de RSE llevadas a cabo por esta multinacional agroalimentaria y cómo, al menos en lo que refiere a la dimensión laboral y a los derechos de los trabajadores, las iniciativas de responsabilidad social desarrolladas son más retóricas que prácticas efectivas que garanticen mejores condiciones laborales para sus trabajadores del Sur. En su estudio Prieto-Carrón se centra en la sede de esta empresa en Nicaragua y analiza el impacto de los códigos de conducta establecidos por la empresa en las mujeres trabajadoras. El código Better Banana Proyject SA8000 incluye las temáticas principales de las leyes laborales nacionales y las convenciones internacionales. Tiene auditores externos que monitorizan el cumplimiento. Incluye algunas referencias a la no discriminación, a la igualdad de oportunidades, pero no dice nada de la promoción de la mujer, la maternidad y el cuidado de los hijos. Mientras los informes y las memorias presentadas para ser auditadas dan cuenta de una realidad concreta en esta temática, la perspectiva de las mujeres trabajadoras de Chiquita es muy distinta. Ellas llaman la atención en la de baja remuneración, la existencia contratos temporales, las largas horas de trabajo, las consecuencias en su salud de usar químicos y obstáculos a la liber- tad de asociación que existen en la empresa. Hablan también de discriminación de género, violación de los derechos de maternidad, acoso sexual, etc. Según muestra Prieto-Carrón (2006) muy pocas de las mujeres que entrevistó para su estudio conocían la existencia del código de conducta de la empresa ni de sus contenidos en materia de regulación laboral. En parte porque muchas de ellas no trabajaban para la empresa directamente sino porque eran contratadas por intermediarios quienes llevaban la gestión del personal. Aspecto que nos permite observar que la dimensión externa de la RSE es aún más difícil de ser cumplida por las empresas. La autora del estudio destaca la sorpresa que despertaba entre las trabajadoras de Chiquita cuando ella les explicaba en qué consistía el código de conducta de la empresa para la que trabajaban directa o indirectamente debido a las diferencias que encontraban existían entre lo que decía el código y sus condiciones laborales. Aún entre aquellas que conocían la existencia del código y las actividades de monitorización que realizaban auditorías externas llamaban la atención sobre condiciones en que se realizaban las mismas, en general, sin buscar la opinión de los trabajadores sobre las condiciones de su trabajo.

En un análisis sobre la misma empresa, pero en este caso en Ecuador, Striffler (2008) muestra la relación que existe entre el cumplimiento de los códigos de conducta y de los acuerdos en materia laboral firmados por la compañía y el peso e importancia de los sindicatos como agentes de denuncia y de control. Desde la perspectiva de Striffler, el acuerdo marco firmado por Chiquita en el año 2001 fue producto de la negociación internacional y de la "formación de alianzas con grupos de solidaridad en los mercados de los países consumidores más importantes, los cuales alternadamente han presionado a Chiquita desde los supermercados" (2008:190). Sin embargo, la empresa respeta el código de conducta que sustenta el acuerdo en aquellas regiones productoras de plátano donde existe mayor presencia sindical y donde las organizaciones de trabajadores son más fuertes. Y al mismo tiempo, intenta desplazar sus actividades comerciales hacia plantaciones menos sindicalizadas como las que caracterizan especialmente a Ecuador y a Guatemala. Striffler (2008) también llama la atención en la negativa de la empresa a enviar auditores a aquellas regiones en donde no está aplicando el código de conducta. 
A pesar de su falta de representatividad estadística, creemos que este caso es paradigmático del funcionamiento de las políticas de RSE. Nos muestra cómo la responsabilidad social empresarial, que toma forma en códigos de conducta y Acuerdos Marco Globales, forma parte aún más de una retórica de responsabilidad social y tiene escaso impacto en la mejora de las condiciones de los trabajadores. Sin embargo, al mismo tiempo, está contribuyendo a la emergencia de un nuevo tipo de regulación laboral "autorreferencial" que convierte a las empresas transnacionales en principales agentes productoras de las mismas. Las empresas transnacionales adquieren en este contexto una posición hegemónica con respecto a los trabajadores y con respecto a las pequeñas empresas. Con respecto a los trabajadores, dada su posición crecientemente vulnerable, las políticas de RSE son presentadas como alternativa a la negociación colectiva que fomentan una individualización de las relaciones laborales (Merino, 2005). Por otro lado, con respecto a los pequeños y medianos empresarios y productores, la incorporación de acciones vinculadas a la RSE puede convertirse en requisito indispensable exigido por las grandes empresas para garantizar y mantener acuerdos comerciales, lo que puede reducir su autonomía y su competitividad. Al mismo tiempo, la "nueva normatividad" (Sassen, 2010) que emerge con este tipo de regulación desplaza al sector privado el tradicional papel del Estado como agente regulador y generador de normas. Sin embargo, esta nueva normatividad y estas nuevas formas de regulación de las relaciones laborales no deben interpretarse sólo desde la perspectiva de la pérdida de poder del Estado y de la merma de las funciones estatales. La dinámica de la globalización opera mediante la labor desnacionalizadora del Estado y también en el ámbito de la regulación laboral, "el Estado surge entonces como un espacio clave para el desarrollo y la instauración de las condicionalidades de la globalización económica empresarial" (Sassen, 2010: 291).

\section{CONCLUSIONES}

En este artículo hemos analizado las convergencias globales registradas en la agricultura a partir de la internacionalización de los procesos productivos y de las nuevas formas de competitividad de las em- presas-red en el sistema global alimentario. Especialmente nos hemos centrado en el impacto de estas transformaciones en las condiciones de producción y reproducción social de la fuerza de trabajo agrícola. El análisis de estas tendencias pone de manifiesto que las regiones privilegiadas por la globalización agroalimentaria se muestran incapaces de contener las contradicciones laborales y sociales de su propio crecimiento. En efecto, la exigencia de disponibilidad de mano de obra flexible y móvil que demanda el mercado de trabajo agrícola ha traído consigo el surgimiento de una nueva estructura social jornalera crecientemente segmentada. Jornaleros y jornaleras agrícolas que, como hemos visto, se enfrentan a distintas formas de segregación, vulnerabilidad social y precarización de sus condiciones de vida y de trabajo. La internacionalización de la economía agroalimentaria plantea, por tanto, un profundo problema de regulación.

En el marco de los procesos de globalización política y económica, la des-regulación de las actividades productivas se ha traducido en una pérdida de poder de los estados y de las organizaciones de trabajadores para actuar como agentes capaces de regular las relaciones laborales. Es en este contexto en el que debemos situar la emergencia de nuevas formas de regulación vinculadas al desarrollo de instrumentos de RSE que, como hemos visto, convierten a las empresas transnacionales en una importante fuente de normatividad en las relaciones laborales. A falta de una regulación pública, podríamos afirmar, se acentúan las relaciones y jerarquías de poder dentro de las cadenas globales de producción en favor de las empresas transnacionales.

En 1995 Charles Tilly, en un artículo con el expresivo título de "la globalización amenaza los derechos laborales", afirmaba que la globalización amenaza la estabilidad de los derechos laborales ya que estaría socavando la capacidad del Estado para garantizar su vigencia y planteaba la idea de qué autoridad garantizaría el cumplimiento de los mismos. Sin autoridad, nos dice Tilly, los derechos no existen. El análisis realizado en este artículo muestra, en primer lugar, cómo la autoridad se está trasladando a agentes privados encargados de crear las normas y "testificar" el cumplimiento de unos códigos de conducta voluntarios y, en muchos casos, unilaterales. En segundo lugar, la promoción que a nivel estatal están teniendo las iniciativas de RSE permite afir- 
mar que, no es sólo la globalización económica ni los actores económicos globales los que socavan la capacidad reguladora del Estado sino que, al mismo tiempo, son los propios Estados los que, convirtiéndose "en espacios estratégicos para la estructuración global" (Sassen, 2010), se erosionan así mismos y contribuyen a construir nuevas geografías de poder.

En este análisis nos hemos centrado sobre todo en uno de los tipos específicos de internacionalización de la regulación; sin embargo, coincidimos con Pries (2008) en que, para analizar el impacto de esta emergente regulación transnacional de las relaciones laborales, deberíamos estudiar la "textura de redes emergente de regulación laboral internacional" existente y las relaciones entre cada una de ella en las arenas que les dan forma. Siguiendo a Pries, el desafío será entonces indagar cómo se articula esta textura de redes de regulación y qué impacto tiene en las condiciones laborales de los trabajadores agrícolas.

Pero esta articulación se enfrenta a una cuestión de considerable calado que dejaremos planteada para finalizar este artículo. Los desarrollos de la teoría de la regulación (Aglietta, 1979; Boyer, 1992) nos enseñaron en sus análisis del periodo de crecimiento capitalista de postguerra que las regulaciones sociales del trabajo no son independientes de otros mecanismos de regulación relativos a la moneda, la competencia inter-empresas, el Estado o las Relaciones Internacionales. Todas estas formas institucionales conforman interdependientemente un modo de regulación. El ejemplo histórico de lo que los teóricos regulacionistas denominaron periodo fordista-keynesiano muestra que el modo de regulación garantiza la sostenibilidad de régimen de acumulación y viceversa. Numerosos analistas, confrontados al examen de las condiciones sociales e institucionales de la etapa de crecimiento económico abierta tras la crisis de los 70 (véase, entre otros muchos, Tickell y Peck, 1995) subrayan el hecho crucial de que el régimen de acumulación flexible y global desplegado desde los años 80 no ha generado ni mucho menos estabilizado un modo de regulación propio: "la geografía de la glocalización es la geografía del después de la crisis fordista, no la geografía del postfordismo estable. Tal estabilidad no puede ser conquistada hasta que el neoliberalismo no sea derrotado. Con el fin de conseguir el prerrequisito esencial de la capacidad de reproducción continuada y sostenible del modo de crecimiento, el nuevo modelo de regulación debe ser uno de carácter anti-neoliberal" (Tickell y Peck, 1995: p. 381). Aunque efectivamente los trazos de un nuevo régimen agroalimentario de acumulación sean bien visibles (McMichael, 1994 y 1995), todo apunta a que mientras las instituciones económicas continúen adheridas a los postulados neoliberales persistirá la problemática de la regulación social, y con ello las incertidumbres e inestabilidades propias de ese modo de crecimiento.

\section{BIBLIOGRAFÍA}

Aglietta, M. (1979): Regulación y crisis del capitalismo, Siglo XXI, Madrid.

Alzamora, M., De Castro, C. Gadea, E., Moraes, N. y Pedreño, A. (2010) "Efectos de la crisis del trabajo sobre la Murcia inmigrante en un contexto europeo de renacionalización de las fronteras", en Foro Ciudadano de la Región de Murcia (ed): El otro estado de la Región. Informe 2010, Murcia, Diego Marín.

Anker, R., Chernyshev, I., Egger, P., Mehran, F. y Ritter, J.A. (2003) “La medición del trabajo decente con indicadores estadísticos”, Revista Internacional del Trabajo, vol. 122 (2003), n 2. Ginebra, OIT.

Aparicio, J. (1997): “El Derecho del Trabajo ante el fenómeno de la internacionalización”, Contextos n” 1, pp. 59-67.

Aragón J; Rocha, F.; y Cruces, J. (2005) La dimensión laboral de la RSE; un análisis de casos. Cuadernos de Información Sindical, La dimensión laboral de la Responsabilidad Social de las Empresas, Editora $1^{\circ}$ de mayo, Madrid, pp. 33-70.

Ardilla, Z. y UlloA, M. (2002) "Mujeres y flores: flexibilización en marcha. El trabajo de las mujeres floricultoras de Colombia", Revista Áreas, vol. 22. (Monográfico sobre Trabajo y sociedad en los campos de la globalización agroalimentaria), Murcia, Universidad de Murcia.

AvellÁ, LL. y VegA, V. (2002) "El mercado de trabajo agrario en la Comunidad valenciana: equilibrio global versus desequilibrios espaciales y temporales”, Revista Áreas, vol. 22. (Monográfico sobre Trabajo y sociedad en los campos de la globalización agroalimentaria), Murcia, Universidad de Murcia. 
BAYLos, P.A. (1999): “Globalización y Derecho del Trabajo: Realidad y Proyecto”, Cuadernos de Relaciones Laborales $\mathrm{n}^{\mathrm{o}} 15$, pp. $20-49$.

BAYLos, P.A. (2009): "Un instrumento de regulación: empresas transnacionales y acuerdos marco globales", Cuadernos de relaciones laborales, Vol. 27, $\mathrm{n}^{\mathrm{o}} 1$, pp. 107-146.

Bendini, M. y Steimbreger, N. (2010): “Trabajadores golondrinas y nuevas áreas frutícolas. Las mismas temporadas, otros territorios", en Lara, S. (coord.): Migraciones de trabajo y movilidad territorial, México, Miguel Ángel Porrúa.

Bendini, M., Steimbreger, N. y Radonich, M. (2011): "Emergencia de viejos temas en un contexto modernizado: marco teórico metodológico en estudio de migrantes estacionales al sur de argentina”, Política y Sociedad, Madrid, Universidad Complutense de Madrid (en este número).

Benencia, R. (2011): "Predominio de inmigrantes bolivianos en los eslabones estratégicos de la cadena agroalimentaria de la horticultura en fresco de la argentina", Politica y Sociedad, Madrid, Universidad Complutense de Madrid (en este número).

Benencia, R. y Quaranta, G. (2002) "Producción de frescos de exportación y desarrollo del capitalismo en América Latina. El caso de Argentina", Revista Áreas, vol. 22. (Monográfico sobre Trabajo y sociedad en los campos de la globalización agroalimentaria), Murcia, Universidad de Murcia.

BILBao, A. (1997): El accidente de trabajo: entre lo negativo y lo irreformable, Madrid, Siglo XXI.

Boyer, R. (1992): La teoría de la regulación, Valencia, Edicions Alfons el Magnànim.

C. De Grammont, H.; Lara, S. y Sanchez, M. (2003): “Caractéristiques des migrations rurales á l'intérieur du Mexique et vers les États-Unis", Migrations et Société, no 87-88, pp: 23-34.

CANDEla, P. y Piñón, J. (2005) "Mujeres entre naranjas: las trabajadoras de los almacenes valencianos de manipulación y comercialización de cítricos" en Castillo, J. (dir.) El trabajo recobrado. Una evaluación del trabajo realmente existente en España, Madrid, Miño y Dávila Editores.

Castellanos, Ma L. y Pedreño, A. (2001) "Desde el Ejido al accidente de Lorca. Las amargas cosechas de los trabajadores inmigrantes en los milagrosos vergeles de la agricultura mediterránea”, Sociología del Trabajo, nueva época, $\mathrm{n}^{\mathrm{o}} 42$, pp. 3-31.

Cavalcanti, J.S.B., Da Mota, D y Gama, P. ( 2002) "Mirando hacia el Norte: clase, género y etnicidad en los espacios de fruticultura del nordeste de Brasil”, Revista Áreas, vol. 22. (Monográfico sobre Trabajo y sociedad en los campos de la globalización agroalimentaria), Murcia, Universidad de Murcia.

Cerfeda, W. (2005): "El sindicalismo europeo ante la responsabilidad social empresarial", Cuadernos de Información Sindical, La dimensión laboral de la Responsabilidad Social de las Empresas, no. 63: 7-18.

CES (2001) Condiciones de trabajo en el sector agroalimentario de la Región de Murcia, Murcia, Consejo Económico y Social de la Región de Murcia.

CHECA, F. (1995): "Del riesgo de las pateras a la supervivencia en los invernaderos", Economía y sociología del trabajo, n $29-30$, pp. 1995.

Checa, J. C. y Arjona, A. (2007): "Factores explicativos de la segregación residencial de los inmigrantes en Almería", Revista internacional de sociología, $\mathrm{n}^{\mathrm{o}} 48,2007$, pp.173-200.

Columbares (1997): Censo y caracterización de las infraviviendas usadas por inmigrantes en la Región de Murcia, Madrid, IMSERSO.

Cooperativas Agrarias (2008): Informe sobre la Responsabilidad Social en las Empresas. Junio.

CoRiat, B. (1993): El taller y el robot, Madrid, Siglo XXI.

De LuCAS, J. (2002) “Algunas propuestas para comenzar a hablar en serio de política de inmigración”, en De Lucas, J. y Torres, F. (eds.) Inmigrantes, ¿cómo los tenemos?, Madrid, Talasa, pp. 23-48.

Durand, J. (2007): Braceros. Las miradas mexicana y estadounidense. Antología (1945-1964), México, Universidad Autónoma de Zacatecas-Miguel Ángel Porrúa-Senado de la República. LX Legislatura.

FISHER, LL. (1964), “The harvest labor market in California”, Quarterly Journal of Economics, Vol. LXV, Washington.

Friedland, W. (1994b), “La nueva globalización: el caso de productos frescos”, en Bonanno, A., La globalización del sector alimentario, Madrid, MAPA.

Friedland, W. (1994b), "The Global Fresh Fruit and Vegetable System: An Industrial Organization Análisis", en Mcmichael, P., The global restructuring of agro-food systems, Ithaca \& London, Cornell University Press.

Friedland, W. H. (1984): "Commodity systems analysis: an approach to the sociology of agriculture", Research in Rural Sociology and Development, vol.1.

Friedland, W., Barton, A. y Thomas, R. (1981), Manufacturing Green Gold. Capital, labor, and technology in the lettuce industry, Cambridge, Cambridge University Press.

Friedland, W. (1982) “The End of Rural Society and the Future of Rural Sociology”, Rural Sociology, Vol. 47 , № 4. 
Friedland, W. (1991) "Introduction: Shaping the New Political Economy of Advanced Capitalist Agriculture", en Friedland, W.,Busch, Buttel, F. y Rudy, A. (eds.), Towards a New Political Economy of Agriculture, Westview Press, Boulder Co.

FrIEdLAND, W. (1997): “Commentary on part III: creating space for food and agro-industrial Just in Time”, en Goodman, D. y Watts, M. (eds.): Globalising food, London, Routledge, pp. 226-232.

Friedland, W. (2001), "Reprise on Commodity Systems Methodology", International Journal of Sociology of Agriculture and Food, Volume 9, Number 1.

Friedmann, H. (1993), "The Political Economy of Food: a Global Crisis”, New Left Review n 197.

Friedmann, H. y Mcmichael, P. (1989), “Agriculture and the State system. The rise and decline of national agricultures, 1870 to the present", Sociologia Ruralis, Vol. XXIX, No 2.

GadeA, E. y Albert, M. (2011): “Asociacionismo inmigrante y renegociación de las identificaciones culturales", Política y Sociedad, Vol. 48, $\mathrm{n}^{\circ}$ 1, pp. 9-25.

García De Cortázar y Nebreda, C. (2008): "Políticas comunitarias en RSE", Ponencia presentada en la Jornada políticas y prácticas de responsabilidad social Foro RSE.

García Hidalgo, J. O. (2001): "Situación actual de los jornaleros agrícolas en México", en: Sedesol, Jornaleros agrícolas, Secretaría de Desarrollo Social, México, pp. 21-59.

García, I. y PedreÑo, A.( 2002) "La inserción de la inmigración extranjera en las áreas agroexportadoras mediteráneas” en De Lucas, J. y Torres, F. (eds.), Inmigrantes, ¿cómo los tenemos?, Madrid, Talasa, pp. 98-119.

Gereffi, G. (1995): “Global production systems and third world development”, en Stallins, B. (ed.): Global change, regional response. The new international context of development, Cambridge, Cambridge University Press.

Gereffi, G. y Korzeniwicz, M. (eds.)(1994): Commodity Chains And Global Capitalism, Westport, Praeger.

GHAI, D. (2003) Trabajo decente. Concepto e indicadores, Revista Internacional del Trabajo, vol. 122 (2003), núm. 2. Ginebra, OIT.

GonzÁlez ChÉvez, L. (2009): “Movilidad laboral. Imposición estructural para la incorporación indígena a los mercados de trabajo en contextos globales", Migración y Desarrollo, no 13, pp.47-59.

Hernández Zubizarreta, J. (2007): "Las empresas transnacionales españolas en América Latina. Los códigos de conducta como sistemas atípicos de regulación de las relaciones laborales". Comunicación presentada al Congreso el desafío del desarrollo humano. Propuestas locales para otra globalización. Bilbao.

HERNÁNDEZ ZuBIZARRETA, J. (2009): Las empresas transnacionales frente a los derechos humanos: historia de una asimetría normativa de la responsabilidad social corporativa a las redes contrahegemónicas transnacionales, Bilbao: Hegoa.

Informe del Foro Mundial sobre Agroindustrias (2008): Aumento de la competitividad y las repercusiones en el desarrollo. Nueva Delhi, abril.

Korovkin, T. y Sanmiguel-Valderrama, O. (2007): "Estándares de trabajo e iniciativas no estatales en las industrias florícolas de Colombia y Ecuador”, Iconos. Revista de Ciencias Sociales, no 29, septiembre: 15-30.

LARA, S. (2005): "Características de las migraciones rurales hacia regiones hortícolas en el noroeste de México", en Hernández Moreno, M ${ }^{a}$ C. y Maya Ambía, C. J., Nueva ruralidad, viejos problemas, Tomo II, AMER/Gobierno del Estado de Zacatecas/ CONACyT/editorial praxis, México, 2005.

LARA, S. (2006): "Mercado de trabajo rural, nuevos territorios migratorios y organizaciones de migrantes", ponencia presentada al V Congreso Nacional AMET, Oaxtepec, 17-19 de mayo.

LARA, S. (2008) “¿Es posible hablar de un trabajo decente en la agricultura moderno-empresarial en México?” en El cotidiano, vol. 23, núm. 147, México, Universidad Autónoma Metropolitana de Azcapotzalco, pp. 25-33.

LARA, S. (2010): “Los 'encadenamientos migratorios' en regiones de agricultura intensiva de exportación en México", en LARA, S. (coord.): Migraciones de trabajo y movilidad territorial, México, Miguel Ángel Porrúa.

LARA, S. (2011) "Los territorios migratorios como espacios de articulación de migraciones nacionales e internacionales. Cuatro casos del contexto mexicano", Política y Sociedad, Madrid, Universidad Complutense de Madrid (en este número).

MARAÑón, B. (2002) “Impactos socioeconómicos y ambientales en la modernización agroexportadora no tradicional en El Bajío, Mexico", Revista Áreas, vol. 22. (Monográfico sobre Trabajo y sociedad en los campos de la globalización agroalimentaria), Murcia, Universidad de Murcia.

Marsden, T (1997): "Creating space food: the distinctiveness of recent agrarian development" en Goodman, D. y Watts, M. (eds.): Globalising food, Routledge, London.

Martin, E. (2002) "Cultivando el racismo: procesos de segmentación laboral y exclusión social en el medio rural andaluz" en Revista Áreas, vol. 22. (Monográfico sobre Trabajo y sociedad en los campos de la globalización agroalimentaria), Murcia, Universidad de Murcia. 
MArtin, P. (2002) “El trabajo en la agricultura industrial. El caso de los EE.UU.” en Revista Áreas, vol. 22. (Monográfico sobre Trabajo y sociedad en los campos de la globalización agroalimentaria), Murcia, Universidad de Murcia.

Martin, P. (2007): "Towards effective Temporary Worker Programs: Issues and challenges in industrial countries", International Migration Papers, Num. 89, Geneva, International Labour Office.

Martínez Veiga, U. (2001): “Organización del trabajo y racismo. El Ejido (España) en el año 2000”, Migraciones Internacionales, Vol. 1, n⿳ 1, pp. 35-64.

Mcmichael, P. (1994), "Introduction: Agro-Food System Restructuring-Unity in Diversity”, en Mcmichael, P., The global restructuring of agro-food systems, Ithaca \& London, Cornell University Press.

MCMichael, P. (ED.) (1995): Food and agrarian orders in the World Economy, Praeger, London.

Mcwillams, C. (1939), Factories in the field. The story of migratory farm labor in California, University of California Press, Berkeley.

Merino Segovia, A. (2005): "Responsabilidad social corporativa: su dimensión laboral” Documentación laboral, n 75: $51-80$.

Ministerio de Trabajo e Inmigración (2008): Las políticas de impulso de la RSE. El Consejo Estatal de la RSE, septiembre.

Moreno, J. (2009): "Los contratos en origen de temporada: mujeres marroquíes en la agricultura onubense", Revista de Estudios Internacionales Mediterráneos, $\mathrm{n}^{\mathrm{o}}$ 7, pp. 58-78.

Moreno, J. (2011) "Movilidad transnacional, trabajo agrícola y género: trabajadoras marroquíes en la agricultura onubense" en Politica y Sociedad, Madrid, Universidad Complutense de Madrid (en este número).

PAlerm, J. V. (1999): "Las nuevas comunidades mexicanas en los espacios rurales de los Estados Unidos de América: a propósito de una reflexión acerca del quehacer antropológico", Areas, 19, pp. 153-180.

PAlerm, J. V. (2010): "De colonias a comunidades: la evolución de los asentamientos mexicanos en la California rural”, en LARA, S. (coord.): Migraciones de trabajo y movilidad territorial, México, Miguel Ángel Porrúa.

Peck, J. (1996): Work Place. The Social Regulation of Labor Markets, The Guilford Press, New York \& London.

Pedreño, A. (1998) “Taylor y Ford en los campos. Trabajo, género y etnia en el cambio tecnológico y organizaciones de la agricultura industrial murciana”, Sociología del Trabajo, nueva época, no 35, pp. 25-56.

Pedreño, A. (1999): Del jornalero agrícola al obrero de las factorías vegetales. Madrid, Ministerio de Agricultura, Pesca y Alimentación.

PEDREÑo, A. (2003) “Trabajadores inmigrantes y agricultura intensiva: por qué vinieron a recolectar frutas y hortalizas a los campos del Mediterráneo español y cómo fueron convertidos en fuerza de trabajo vulnerable y disponible" en Tornos, A. (ed) Los inmigrantes y el mundo del trabajo, Madrid, Universidad Pontificia de Comillas.

Pedreño, A. (2005) "Sociedades etnofragmentadas” en Pedreño, A. y Hérnández, M (coord.) La condición inmigrante. Exploraciones e investigaciones desde la Región de Murcia, Murcia, Ediciones de la Universidad de Murcia.

Pedreño, A. y RiQuelme, P. J.; (2006) La condición inmigrante de los nuevos trabajadores rurales en Revista de Estudios agrosociales y pesqueros, 211, pp. 189-233.

Pizarro, C. (2009): “Ciudadanos bonaerenses-bolivianos: Activismo político binacional en una organización de inmigrantes bolivianos residentes en Argentina", Revista Colombiana de Antropología, Vol. 45, n², pp: 431-467.

Pries, L. (2008): "La emergencia de un tejido de regulación laboral transnacional", Sociología del Trabajo, nueva época, $\mathrm{n}^{\circ} 63: 27-48$.

Prieto-Carrón, M. (2006): “Corporate Social Responsibility in Latin America Chiquita, Women Banana Workers and Structural Inequalities”, $J C C \mathrm{n}^{\mathrm{o}} 21$ Spring: 1-10.

Radonich, M., Steimbreger, N. y Ozino, M. (1999): “Cosechando temporadas”, en Bendini, M. y Radonich, M. (coord.): De golondrinas y otros migrantes. Cuaderno GESA II. Buenos Aires, Editorial La Colmena.

ReigadA, A. (2010) "El impacto de la reestructuración productiva en los mercados de trabajo agrícolas: el caso del cultivo de la fresa en Huelva" en DE CASTRO, C., Gadea, E., Moraes, N. y Pedreño, A. (eds) Mediterráneo Migrante. Tres décadas de flujos migratorios, Murcia, Ediciones de la Universidad de Murcia.

ReigadA, A. (2011) "Más allá del discurso sobre la 'inmigración ordenada': contratación en origen y feminización del trabajo en los campos de fresas" en Politica y Sociedad, Madrid, Universidad Complutense de Madrid (en este número).

Río Ruiz, M. A. (2002): El Disturbio de el Ejido y la Segregación de los Inmigrantes. Andulí. Revista Andaluza de Ciencias Sociales. Núm. 1. pp. 79-107.

SALDAÑA, A. (2009): "La construcción del territorio circulatorio de una comunidad nahua del Alto Balsas", en Sánchez, K. y Saldaña, A. (coord.): Buscando la vida. Productores y jornaleros migrantes en Morelos, México, Plaza y Valdés. 
SÁnchez, K. (2006) Los capitanes de Tenexpango. Un estudio sobre la intermediación cultural, México, UAM.

SÁNCHEZ, K. (2011) "Un enfoque multidimensional sobre los intermediarios laborales en el medio agrícola” en Política y Sociedad, Madrid, Universidad Complutense de Madrid (en este número).

SÁnchez, K. y Saldaña, A. (2009): “Comunidades migrantes: los cortadores de okra en Morelos”, en Sánchez, K. y Saldaña, A. (coord.): Buscando la vida. Productores y jornaleros migrantes en Morelos, México, Plaza y Valdés.

SANDERSON, S. (1986): "The emergence of the world sterr: internationalization and foreign domination in Latin American cattle production", en F. L. Tullis y W. L. Hollist (eds.): Food, the State and International Political Economy, Lincoln: University of Nebraska Press, pp. 123-148.

SAssen,S. (1988) La movilidad del trabajo y del capital, Madrid, Ministerio de Trabajo.

Sassen, S. (1999) Guests and Aliens, New York, The New Press.

SASSEN, S. (2001): La ciudad global, Eudeba, Buenos Aires.

SASSEN, S (2010): Territorio, autoridad y derechos. De los ensamblajes medievales a los ensamblajes globales. Buenos Aires: Katz.

SAssone, S. M. (2007): "Migración, territorio e identidad cultural: construcción de "lugares bolivianos", Población de Buenos Aires, n 6, pp. 9-28.

Segura, P. y Pedreño, A. (2006): "La hortofruticultura intensiva de la Región de Murcia: un modelo productivo diferenciado", en Etxezarreta, M. (coord.): La agricultura española en la era de la globalización, MAPA, Madrid.

Segura, P., Pedreño, A. y De Juana, S. (2002) “Configurando la Región murciana para las frutas y hortalizas: racionalización productiva, agricultura salarial y nueva estructura social del trabajo jornalero" en Revista Áreas, vol. 22. (Monográfico sobre Trabajo y sociedad en los campos de la globalización agroalimentaria), Murcia, Universidad de Murcia.

SteinBeck (1936/2007): Los vagabundos de la cosecha, Los Libros del Asteroide, Barcelona.

STORPER, M. (1991): Industrialization economic development and the regional question in the third world, Pion Limited, London.

Storper, M. y Harrison, B: (1994): "Flexibilidad, jerarquía y desarrollo regional: los cambios de estructura de los sistemas productivos industriales y sus nuevas formas de articulación del poder en los años 90”, en BENKO, G. y LIPIETZ, A. (eds.): Las regiones que ganan: distritos y redes. Los nuevos paradigmas de la geografía económica, edicions Alfons el Magnànim, Valencia.

Striffler, S. (2008): "El fruto del neoliberalismo: Organización laboral transnacional en el contexto de la industria bananera global, y el caso ecuatoriano", Clio America nº (2): 179-194.

TARrius, A. (2000): "Describir, Interpretar. Las circulaciones migratorias: conveniencia de la noción de 'territorio circulatorio'. Los nuevos hábitos de la identidad", Relaciones, vol. 21, nº 83, pp. 39-66.

Tickell, A. y PeCK, J. (1995): "Social regulation after fordism: regulation theory, neoliberalism and the global-local nexus", Economy and Society, volume 24, n 3, pp. 357-386.

Tilly, CH. (1995): "Globalization threatens labors Rights", International and Working-Class Hitory, n47: 1-23.

Torres PÉrez, F. (2002): “Inserción laboral e inserción social de los inmigrantes en las áreas agroexportadoras mediterráneas: La importancia de los contextos locales", Areas, nº 22, pp. 129-140.

Torres Pérez, F. (2009): "La inserción residencial de los inmigrantes en la costa mediterránea española: 1998-2007, co-presencia residencial, segregación y contexto local", Areas, n 28 , pp. 73-87.

Torres PÉrez, F. (DIR.) (2007): Los nuevos vecinos de la mancomunidad del sureste: los inmigrantes y su inserción en Torre Pacheco, Fuente Álamo y La Unión (Murcia), Murcia: Universidad de Murcia.

Velasco Ortiz, L. (2002): “Agentes étnicos transnacionales: las organizaciones de indígenas migrantes en la frontera México-Estados Unidos”, Estudios Sociológicos, Vol. 20, nº 59, pp. 335-369.

Viruela Martínez, R. (2010): "Movilidad geográfica de los rumanos (Estructura territorial de las migraciones interiores en España)", Empiria, n 19, pp. 157-181.

WALlERSTEIN, I. (1979): El moderno sistema mundial. La agricultura capitalista y los orígenes de la economía-mundo europea en el siglo XVI, Siglo XXI, Madrid.

WatTs, M. y Goodman, D. (1997): “Agrarian questions. Global appetite, local metabolism: nature, culture and industry in fin-de-siecle agro-food systems”, en Goodman, D. y Watts, M. (eds.): Globalising food, Routledge, London. 